time by redistillation and used again. By this method dialysis can be carried out at room temperature without any danger of bacterial infection because of the alcohol or acetone medium in which the dialysis is made.

No inactivation during the experiment was observed. The enzyme solution is poured into a Cellophane bag, the mouth of which is tied securely about a glass tube made of a test tube, large enough to permit the addition or removal of the solution. The Cellophane bag with its protruding glass tube is suspended within a tall beaker into which the alcohol is introduced, submerging the Cellophane bag and its contents and allowing diffusion of the water from the solution into the alcohol. For about $50 \mathrm{ml}$. of solution being concentrated we used $200 \mathrm{ml}$. alcohol. Within 3-8 hours the original volume is reduced to about one tenth. If the alcohol is changed two or three times, the time of concentration is reduced by half.

Part of the enzyme is precipitated during concentration and forms a deposit on the Cellophane. The concentrated solution is taken out by a pipette or by tearing the Cellophane, and precipitated with an equal volume of absolute alcohol or acetone. After centrifugation and washing with ether, the substance and the Cellophane coated with the active substance are dried in a desiccator over sulphuric acid.

It is possible by dialysing over a longer time to remove completely all the water of the active solution and to obtain the active substance as a precipitate on the Cellophane. After drying the Cellophane in the desiccator or in air, the substance can easily be separated from the Cellophane. If but minute quantities of enzyme were in the solution the dried Cellophane with the deposit on it can be introduced in water which dissolves the substance. We employed this procedure for the concentration of taka-diastase, pancreatin, pepsin (all from Parke Davis and Co.) and yeast extract protease, as well as in preparing papain from Carica papaya latex from Jericho, Palestine, for which I am indebted to the Department of Agriculture of the Palestine Government.

All the enzymes were obtained in a dry, active form. It remains still to be seen whether the method may be employed for the concentration of desmolytic enzymes as well as other biologically active substances. JACOB Feigenbaum.

Chemical Department, Cancer Research Laboratories,

The Hebrew University, Jerusalem.

1 Youngbourg, Guy E., Science, 94, 498 (1941).

${ }^{2}$ Feigenbaum, J., Science (in the press).

\section{A Mucorine Parasite on Penicillia}

IN the course of blowing experiments on air-dried soils, by use of an adaptation of a simple type of 'spore-blower' recently described', a growth of Piptocephalis was obtained which proved to be parasitic on Penicillia.

This has now been in culture for more than a year. The original Penicillium from the soil, on which it was first found, has not yet been satisfactorily named, but the parasitism of the Piptocephalis on it has been fully confirmed by observation. The parasite has also been obtained in culture on a number of other unnamed Penicillia, and on the following named cultures : Penicillium roqueforti, $P$. notatum (Fleming's strain), $P$. pfefferianum, $P$. glabrum. It has failed to grow on $P$. camemberti, on a member of the Biverticillata Symmetrica, on several fasciated Penicillia, and on a number of common Hyphomycetes of different genera.

Among the Mucorales it has so far been obtained in growth on Mucor mucedo + and - , and $M$. hiemalis + and - , but has not grown on a wide range of other Mucorales. Growth on the Mucors is distinctly sparser than on the Penicillia, on which it is dense and luxuriant.

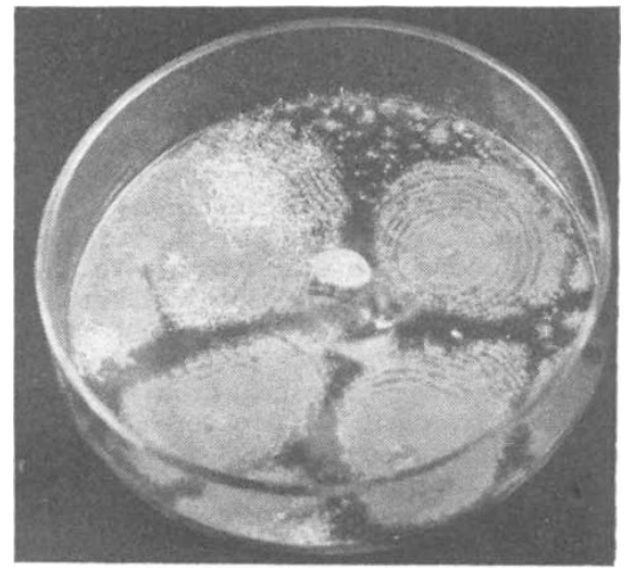

Piptocephalis sp. on Penicillium

The Piptocephalis does not correspond closely to any described species, but it is nearest to P. Tieghemiana Matruchot ${ }^{2}$. Its special interest lies in the fact that, so far as I can discover, no mucorine parasite has hitherto been reported as growing on a mould other than another member of the Mucorales. Matruchot, in $1903^{3}$, based his view that Cunninghamella is a member of the Mucorales chiefly on its ability to act as host to $P$. Tieghemiana, which would grow only on Mucors, and in most works dealing with it the genus Piptocephalis is said to be parasitic only on the Mucorales.

The breaking down of this generalization may perhaps lessen the imaginary gap between the Mucors and the Plectomycetes, and at the same time discourage the tendency to regard mucorine parasitism in general as a phenomenon related to sex and based upon close physiological relationship.

So far as can be seen at present the ability to support this parasite cuts across the ordinary divisions of the Penicillia, and it is possible that, since the parasitism when it occurs appears to be strongly marked, and to result in a conspicuous growth of white (ageing to buff) 'conidiophores' above the host (see photograph), it might provide in some cases a useful additional character for distinguishing Penicillia.

Since this note has gone to press the Piptocephalis has been obtained in profuse growth on Aspergillus niger. This enlarges considerably the scope of its parasitism.

A detailed study of its morphology is now being undertaken by Miss M. P. English.

Botany Department,

King's College, London.

C. G. Dorbs.

(At the University, Bristol, 8.) August 12.

${ }^{1}$ Dobbs, C. G., New Phytol., 41, 63 (1942).

Matruchot, L., Bull. Soc. Mycol. de France, 16, 58 (1900).

${ }^{3}$ Matruchot, L., Ann. Mycol., 1, 45 (1903). 